\title{
A joint effort to fight arthritis
}

$\mathrm{L}$ inda Wilhelm's knees are not the ones she was born with. Her shoulder joints are also artificial, as is one hip. Since being diagnosed with rheumatoid arthritis in 1983, the New Brunswick mother of three has also tried a host of medications. She calculates that over a decade, the province spent about half a million dollars to meet her medical needs.

There were times during her struggle with arthritis when she was bound to a wheelchair. There were times she couldn't dress herself. Now Wilhelm is doing much better, and has even taken up kayaking, thanks to the care she receives from a team of doctors, physiotherapists and other health care providers.

"It took me 20 years to assemble my health care team. ... I had to develop that team myself," Wilhelm said Sept. 18 in Calgary, Alberta, at the launch of Joint Action on Arthritis: A Framework to Improve Arthritis Prevention and Care in Canada (www.arthritisalliance .ca/docs/media/201209171000_frame work_EN_588.pdf).

Ensuring that people such as Wilhelm are no longer forced to organize their own care through trial and error is one the primary goals of the initiative led by the Arthritis Alliance of Canada. It proposes national adoption of a threepillar approach to improve the lives of an estimated 4.6 million Canadians who are living with arthritis: advance knowledge and awareness; improve prevention and care; and support ongoing stakeholder collaboration.

With regard to knowledge, much of what people believe about the chronic condition are actually myths, says Dr. Dianne Mosher, president of the alliance. It is not a natural part of the aging process. It is not an old person's disease. It is not a condition for which little can be done. "I think what we need to do is have common messaging," she says. "Collectively, all of the groups we have gathered around the table, we need to be saying the same

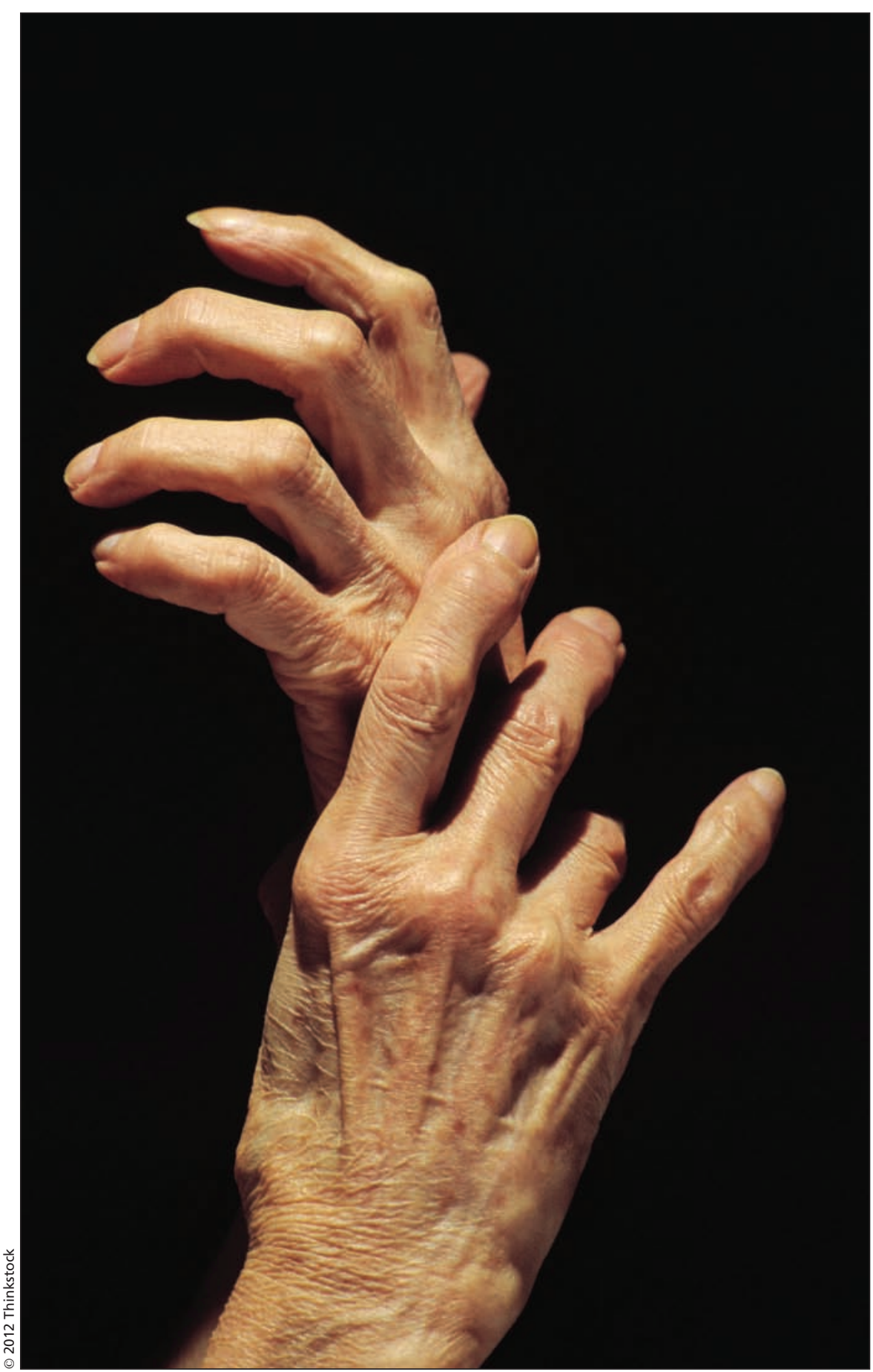

Osteoarthritis, a progressive joint disease, affects a projected one in eight Canadians.

things. That arthritis is not 'an inevitability.' That it's not just about taking an Aspirin and going to bed. There are things we can do."
The second pillar, improving care and prevention, can be achieved through self-management strategies and the adoption of evidence-based models of 
care delivery, states the report. "While many guidelines are available, there are few validated quality indicators and tools to evaluate quality of care, and none are in systematic use in Canada. The only area of care that has made substantial progress is the evaluation of wait times for hip and knee replacement surgery. As well, there is no nationwide process for evaluating, improving and disseminating effective models of care."

"Like other chronic diseases, prevention strategies include obesity management and education about obesity in early life and throughout life," says Dr. Cy Frank, co-vice chair of the board of directors of the Alberta Bone and Joint Health Institute. "Stressing the importance of physical activity is another key strategy, not just to manage pain but also to keep your weight down."

The most critical factor in treating rheumatoid arthritis, which causes inflammation of joints and surrounding tissues, is diagnosing it early. The odds of a person requiring joint-replacement surgery drops dramatically with the use of early interventions, such as drug therapy or the injection of biological agents that target inflammation.

"You can't reverse the damage, but you can prevent the damage," says Frank. "A big focus now is on how we can identify rheumatoid arthritis quickly and get the patients through who need therapy."

Increasing collaboration between all stakeholders, from government through to front-line care providers, is also a vital step in improving the quality of life for people with arthritis and reducing the burden of the disease on the health care system. There are pockets of the country that do well in certain areas of improving care, such as providing timely access to orthopedic surgery, and disseminating the best models of practice across the country is imperative, according to the alliance.

"How do you spread best practices?" says Mosher. "It means getting all the people and groups together and having a plan, and working with provincial governments to implement it."

The report notes that the burden of arthritis will increase in Canada "due to increased longevity, reduced physical activity, increasing obesity and lack of access to timely health care. ... Within a generation, more than 10 million (one in four) Canadians are expected to have either osteoarthritis (OA) or rheumatoid arthritis (RA), the two most common forms of arthritis. The total economic burden of OA and RA in Canada, including direct health care costs and productivity losses to the economy, will grow from $\$ 33.2$ billion in 2010 (2.7\% of the value of Canada's Gross Domestic Product) to over $\$ 68$ billion in 2040 (2010 values)."

Although the chronic condition doesn't receive as much as attention from researchers, funding bodies and the public as do deadlier diseases, such as cancer or heart disease, changing demographics will likely make arthritis a more pressing concern. "When we look at our population, we see it's aging, but baby boomers expect to do all the activities they want to do," says Mosher. "And we need people to stay in the workforce." Roger Collier, CMAJ

CMAJ 2012. DOI:10.1503/cmaj.109-4306 